\title{
About the Tradition of Mythological Landscape in Russian Fine Art
}

\author{
Eugeny Moroshkin \\ Russian State Specialized Academy of Arts \\ Moscow, Russia \\ E-mail: e-moroshkin@yandex.ru
}

\begin{abstract}
This article is about the evolution of Russian landscape in fine art that began from the works of Kuindgy. The research focuses on the reviewing the content and the ways to express it, the connection of fine art with the other arts music, poetry, theatre, and the spiritual and professional achievements from the followers of Kuindgy.
\end{abstract}

Keywords-Russian landscape art; Kuindgy; Roerich; Bogaevsky; Chiurlionis; Amaravella

\section{INTRODUCTION}

In the history of fine art it is possible to see how several artists are united by, more or less, the awareness of transphysical reality. They create their own methods of expressing this reality, and when such methods are close enough to each other, they may be considered a type of traditional method.

One of these traditional methods began to appear in Russian landscape art of the 19th century, which aimed to open and show the life of a person through the imagery of nature. At times, through this emotionally colored landscape, the atmosphere shows the desire to create a relationship between one's own emotions and nature itself. This can be seen in the latter works of V. Polenov, A. Savrasov, and I. Levitan.

Arkhip Kuindgy took even more drastic step more drastic step in this direction: he broke away from expressing his mood through a landscape and began to search new forms, which could be interpreted as language of the soul of the nature. He looked at nature more and more poetically. The world seen through his paintings present a veil of mysteriousness, inexpressible and inconceivable by their significance and power.

N. Roerich, K. Bogaevsky, A. Rylov, and V. Purvit were some of the few pupils of his to cherish the precious year at the Academy of Arts and graduated, continuing their activities and searches in the new myth-creating stream. Independents, based on other sources, such as M. Vrubel, M. Chiurlionis, K. Petrov-Vodkin, and P. Kuznetsov also bore their poetic territories by their work in art. Petrov-Vodkin and Kuznetsov also enriched the naturmort genre with the help of new images.
A famous poet of symbolism, M.Voloshin, was the author of many watercolor landscapes, which also represent the poetic tradition. Many credo ideas and formulas of this direction were, for the first time, expressed brightly within Voloshin's poetry and his analyses of various art articles (particularly on themes of art).

Since the mid-1920s, the "Amaravella" art group became the main successor of the tradition, began by Kuindgy. It was continued by Roerich, Vrubel and Chiurlionis. The Amaravella circle united P. Fateev, B. Smirnov-Russetsky, V. Chernovolenko, S. Shigolev, and A. Sardan. Their creative manifesto states: "The power of impression and persuasiveness of artwork depends on the deepness of insight into the Source of creative impulse and inner significance of this Source. Our creative activity, predominantly intuitive, is aimed at disclosure of various aspects of Cosmos in human portraits, landscapes and reflecting abstract images of inward world" [1]. Lithuanian artist Shimonis went parallel and very close to the Amaravella group in his research.

\section{PARAllels BetweEn Fine ARTS AND Other ARTS}

By the beginning of the 20th century, the connection between fine arts and other arts had become more evident.

One of the more important spheres of Roerich's art work was decorative in theatre. It influenced his landscapes, making them more visible. It, however, was a feature of the whole art movement in the beginning of the 20th century. No less must we consider the works of Bogaevsky and Chiurlionis long after it appeared in Kuindgy's famous landscapes of the 1880s.

Many artists many touch on the kindred relations between the fine arts and music. These two arts are successfully interwoven within Chiurlionis' creative life. He used music principles in composing the series of his pictures. They have clear rhythmic organization and predominant colors that associate with music tonality.

Music was one of powerful impulses of Amaravella artists, who tried to generalize and express themselves like musical composers in their pictures. It was especially exemplified in Chernovolenko's work when music improvising awoke his fantasy in fine art improvisation. 
The connection with poetry also is very significant for characterizing such artists as Voloshin, Roerich, Chiurlionis, and Smirnov-Russetsky. In their art, they put forth creative energy to their paintings and literature in proportions, necessary for spiritual and professional tasks.

The lines of Voloshin's poem, written in the beginning of his later period of artwork, can help us understand the aspirations of artists - cosmists, their specific, sometimes, paradoxical, style of expression.

I remember other world

Half cleaned off and not alike

In your world I am a passer

Close to all, to things - alien.

Random row of combinations

Of world powers, roads of world

In this world of closed facets

Poured me and materialized.

For me it's so new and joyful

All what's usual is for you

I love word for fraudulent mist

And limpidity of your eyes.

All your childish understandings

Of the evil, death, love, $\sin -$

World of soul, weared in clothes

Of the saint and falsefull words.

Harmonic but faded flickers

World of things in their sounds

As the patterned stained glass window

In the dark old gothic church. [2]

This poem demands commentary, otherwise one can suppose that the poet is arrogant and has childish concepts, as the majority of mankind tends to be, lacking spiritual vision. The person who didn't lose their vague memory of his pre-existence, higher worlds and their more perfect laws, whose attention and intuition are focused at accepting any hints from these worlds, meets all the catched compliances, every moment in any life sphere when other world shows itself and can be guessed through the veil - all of this respond in this person by great joy and feeling of new.

In the same time he constantly notes distance, that part things and phenomenon around him from their more perfect expressions. The world as he feels it, is shielded from him like a veil, because vised colors are not so bright as they used to be outside from today facets that are closed.

This helps to explain some features of art language of painters from Kuindgy's direction. It is possible to see how they begin with elementary details and make their new method, accenting these details many times with their attentiveness, intuition, comprehension, and analysis of details with their inner vision of the image to create the best language to express the more complicated concepts.

\section{THE SEARCHES FOR THE ELEMENTS OF PICTORIAL LANGUAGE IN LANDSCAPES}

Let's look at the often used elements of this language.

The image of the Earth is often represented in a general way. Landforms are accented, drawings of horizons going one after another (E.g. Roerich', "Ladoga", "The daughter of Viking", "Human Forefathers", "Saint Prokopij is praying for the unknown floating"; "Green necklace" by SmirnovRussetsky).

In the works, devoted to Himalaya, Roerich often makes mountains and gorges look like statues with sharp and often anthropomorphic forms ("Forthcoming", "Ice Sphinx", "Enchanted Kingdom"). Sometimes in the "face" of the mountain you can feel and see enlarged accented qualities of Earth's elements. In one case, an almost cristallic form is underlined and is especially expressed by sharped facets ("Bell Mountain", "Sharughen Monastery", "Treasuries of the snow country").

Sometimes the impression shows the ridges of the mountains are translucent and self-illuminant ("Krishna", "Padma Sambhava"), the mountain can become like a flower that is opening when it blossoms ("The buried treasury"). The mountain can express the Fire element, charging the surrounding area with the energetic tension of bright flame of colors of hot paint or become like the flame itself, the very spurs of it ("Prophecy of Shambala", "Chintamany", "Issa and the head of a Giant").

Many of Kuindgy's pictures and plenty of his sketches show that the artist was inspired by the idea to search the universal principle of opening of the forms in their evolution during life process as it is natural for plants, for clouds - they find their inner kindred relationship, take part in some symbolic universal mystery of nature ("Oaks", "Cloud", "Burch forest" - 3rd version).

Voloshin and Smirnov-Russetsky often make clouds nearly actors play ("Procession", "The Cloud-Bowl", "The Orchestra Conductor" of Smirnov-Russetsky). Bogaevsky's clouds play expressive heaven's performances, associated in style with engraving and trellis art of XVII-XVIII century.

Roerich gives plenty of images within his drawings of clouds. Their palette defines emotional sound of the picture, clouds look like messengers of Heaven, can engage in a dialogue with fibula of the picture ("Celestial Battle", "Omen", "Crowns", "Voice of Mongolia"). "Manuscripts", appearing among clouds, give mythological fabula naivelyallegorical aesthetic that is close to icon ("The Last Angel", "Elijah the Prophet").

Sometimes the point of view of the artist looks situated in open air as if he hovers in space torrents ("The Flight", "Clouds over the mountains" of Smirnov-Russetsky). In his "Rhythms of clouds" the space itself is represented vertically. 
Its layered structure can unite by its rhythm atmosphere, bending horizons and subterranean strata. The same composition in Chernovolenko's "Rus" leads to a new result - ethics, spiritual levels. The upper part of the picture attracts the look to higher spheres, that are mysterious and limitless.

The search of the essence of the Elements makes an artist look attentively at the ground surface, drawing of moss on the soil and stones, mentally going into rocks and underneath the water. Properties of elements can come to the foreground, color all around. Properties of stone can influence the picture entirely with rigid lines of earth, trees and even clouds ("Stone island" of Smirnov-Russetsky, "Sea shore", "Memory of Mantegna" of Bogaevsky, "Tristan's Castle", "Spell Fire" of Roerich). In the Roerich works during the Himalaya and Mongolia expedition, the stone has the message for us about past civilizations and saving their saint drawings.

Artist's look to continue into the Earth. Roerich is interested in legend of different peoples about opening bowels of the mountains, hidden treasuries, underneath human beings. ("Bowels","Guardian of the cave", "Treasure of the mountain"). There can also be fire elements ("Kidnappers fire", "Nibelungs" of Roerich, "Fiery Bridge" of Chernovolenko, "Atlantis" of Smirnov-Russetsky). Chernovolenko's works out his own under-earth mythology, developing it successfully in methods of Chiurlionis and Vrubel. The research from the late period of his art lead him to the investigate the material life, when the essence of Earth is given in a cut, seen from flaming depth to High Heavens ("The structure of the planet", "At the source of Harmony", "Shaping forms").

Besides the underlining stone, crystal properties of nature, there was another art trend - to show soft, fluent forms. It's reflected in Kuindgy's winter landscapes ("Reflections of moonlight in the winter forest", "Spots of sunlight on frost). His winter sketches were continued by pupils to express the feeling of mysterious and unseen life that is covered and hidden ("The Solveig's House", "Snow Guards" by Roerich, "Winter sunset", "The Pike lake" by Smirnov-Russetsky).

Moonlight makes nature and twilight time mysterious and spellbound - this is from a romantic style. Kuindgy enriched this tradition, filled it emotionally and mystically. When the person is staying in front of night nature, his feeling's palette become more cosmic and at the same time more heartedly connected with Earth ("Elbrus moonlit night", "Twilight in the steppe" by Kuindgy, "White Night" by Rylov, "Medieval Revel", "Burning of Darkness" by Roerich, "Silence" by Smirnov-Russetsky).

Kuindgy gives the moon itself a new imaginative solution. Transcendence, detachment from all the Earthy things, intentgazing from height ("Moonlight on the Dnieper", "Daryal Gorge"). Mystical energy from the full moon is given by Roerich, especially in several Himalaya sketches where lapidary drawing is combined with extraterrestrial thickness and refinement of colors. Color accent of the moon is suddenly and loudly added to it.
A special attitude towards the Moon and the Sun as cosmic objects is seen in Voloshin's works - in his watercolors, in many poems, in the crown of sonnets "Lunaria". The planets have enlarged images, the intensity of colors paints the "buzzing sunsets of copper suns" as a mystery of nature, ecstatic density of its forces.

Looking at the underwater world images, artists show soft shapes, transparency of light, a hint of a perfect world ("Underwater kingdom" - Roerich's decoration to "Sadko" opera, "At the bottom of the ocean" of Chernovolenko, works from the series "World creation" and "Sonata of the sea" of Chiurlionis). Underwater sphere also be toned in a more personal fashion, symbolizing the world that is gone to the depths of human memory ("The town of Past" by Shimonis, "Kitezh" by Smirnov-Russetsky).

\section{THE WORLD OF PLANTS IN MYTHOLOGICAL LANDSCAPE}

Comparing Roerich's and his followers' painting with the other landscape-based art schools, the different attitudes towards the kingdom of plants catches the eye. Most landscape painters give the richness of life through nuances of forms and colors of trees. On the contrary, in Roerich's school, plants are often absent, but, when they are present, it is evident that artist had internal complexity to overcome when inviting plants in their world. That's why ornamental stylized forms were preferred in such rare occasions.

Rarely can we see plants in the artist's focus of attention. When it happens, nature space looks closed, sometimes like a cathedral, with its symmetry and rhymes in forms; trees then become sculptural. Eloquent forms express solemnity and reverence ("Birch Grove" of Kuindgy, "Forest river", "Green pattern" of Rylov, "Sacred place" of Roerich, "Birch and willow" of Smirnov-Russetsky).

The artists try to show not material in trees - they look like flickering pattern watercolors of Bogaevsky, like close to theatre decorations in "Autumn" of Kuindgy, "Guga Chochan" of Roerich, "Blossoming apple trees" of SmirnovRussetsky.

Very specific is the tree in Voloshin space. Often ornamental, not suitable in the frame - as if drawn after the picture was finished. His trees look like beings from a parallel world, half translucent, not in contact with a seen world.

Works from the series "Transparency" of SmirnovRussetsky, created during 70 years of his activities since the 1920 s to the 1990s, suggest several styles to express this idea - more realistic, or Art Nouveau, or almost abstract. Reverse perspective was often used by him, the far trees become vague, ethereal and the drawing looks more alike energy fields and lines, changing and charging space, influencing its rhythmic organization ("The light of autumn forest", "Autumn rhythms", "Silverlike transparency"). 


\section{The Organizing Mythological Space}

Analogous solutions can be seen also in open space and in fantasies with architecture motives. Two realities are very close to each other in significant thoughts of artists ("Contemplation", "Lament", "Vortices over the ruins" by Chernovolenko, "Silhouettes in the starry sky", "Watch of Angels" of Smirnov-Russetsky", "Bridges", "Gemaetisky cemetery" by Chiurlionis).

The aspiration to show reality far distant from usual space and object concepts leads artists to such an expressivity of lines and rhythms that space is related to sound waves. That's why, following Chiurlionis, they often give their pictures music names. If Chernovolenko and Shigolev draw other worlds fully based on their inner vision ("The sounding space", "The song of sea", "Hymn to the birth of music" by Chernovolenko, "On a silver bowl", "Laboratory in Cosmos" by Shigolev), the others can't avoid appealing to different art traditions, giving them new, transphysical feelings ("The timbre of the harp", "Thought, material, architecture" by Sardan, "Town of sounds" by Shimonis).

A new reality is opened to the artist, demanding his own self-identification, his decision, and how to behave there. Early Roerich answered to himself: contemplator, hermit, wayfarer. Such a concept of landscape ("The look of wisdom", "Eagle's nest") was continued by SmirnovRussetsky ("In the mountain ashram"), by Shigolev ("Sunny Wind"), by Chernovolenko ("Invincible Spirit", "The height of beauty", "Hermit").

\section{CONCLUSION}

So, we can see, that Kuindgy's art gave the beginning for the big and - as it's seen from intensive evolution - organic tradition for Russian culture - tradition of mythical creations, rethinking and transformation of nature.

If "Moonlight on the Dnieper" and further works of Kuindgy seemed sudden and not connected with art directions of that period, but intensive development of mythological landscape by his followers was included into the context of different art searches of XX century:

- style searches in art-nouveau stream (Bogaevsky, Roerich, Chiurlionis);

- connection with theatre culture of the beginning of the century;

- desire to synthesize the arts (Roerich);

- connection with philosophy of Russian cosmism;

- interest to what art avantguard opened.

Mythological landscaping became a genre that in different branches of expression could reflect complexities of spiritual searches of the new XX century, uniting these searches by one vector and energetic focus on the way of mankind to perfect itself.

\section{REFERENCES}

[1] Amaravella group manifesto. Victor Tihonovich Chernovolenko. Veneration lights (album). Kaliningrad, "Amber tale", 1997, p. 13.

[2] M. Voloshin. Collected Works. V.1. M., "Ellis Lak 2000", 2003, p. 40. 